\title{
Size distribution of FEBEX bentonite colloids upon fast disaggregation in low-ionic strength water
}

\author{
NATALIA MAYORDOMO ${ }^{1, *}$, CLAUDE DEGUELDRE ${ }^{2}$, URSULA ALONSO ${ }^{1}$ \\ AND TIZIANA MISSANA ${ }^{1}$ \\ ${ }^{1}$ CIEMAT, Avenida Complutense, 40, 28040 Madrid, Spain \\ ${ }^{2}$ Paul Scherrer Institute, 5232 Villigen-PSI, Switzerland
}

(Received 31 May 2015; revised 27 November 2015; Guest editor: Reiner Dohrmann)

\begin{abstract}
Bentonite colloids generated from the backfill barrier in nuclear waste repositories may act as radionuclide carriers, if they are stable and mobile. Repository scenarios with highly saline groundwater inhibit colloid stability as particles tend to aggregate but, in the time frame of repositories, groundwater conditions may evolve, promoting particle disaggregation and stabilization. The disaggregation of FEBEX bentonite colloids by fast dilution to lower ionic strength was analysed in this study. Time-resolved dynamic light-scattering experiments were carried out to evaluate the kinetics of bentonite colloid aggregation and disaggregation processes in $\mathrm{Na}^{+}$and $\mathrm{Na}^{+}-\mathrm{Ca}^{2+}$ mixed electrolytes of low ionic strength. Attachment and detachment efficiencies were determined.

Aggregation is promoted by increasing ionic strength, being more efficient in the presence of divalent cations. Once bentonite colloids are aggregated, a decrease in ionic strength facilitates disaggregation, but the process is not fully reversible as the initial size of the stable bentonite colloids at low ionic strength is not fully recovered. Particle-size distribution and concentration in suspension were analysed on disaggregated samples by single particle-counting measurements. Small colloids were measured in the disaggregated samples but their population was smaller than in the initial stable sample, especially in the presence of $\mathrm{Ca}^{2+}$.
\end{abstract}

KEYwords: colloids, FEBEX, disaggregation, bentonite, barrier, nuclear-waste repositories.

Colloids are particles with sizes ranging from $1 \mathrm{~nm}$ to $1 \mu \mathrm{m}$ suspended in a fluid (Hiemenz \& Rajagopalan, 1997). Colloids can be found in natural environments in concentrations of $10^{10}$ particles per litre (Degueldre et al., 1989) and their concentration, under certain chemical conditions, depends heavily on their stability. In low-salinity waters, colloid concentration is greater than in saline environments, where colloids are aggregated and thus the concentration of stable particles decreases (Ryan \& Elimelech, 1996; Degueldre et al., 2000, 2009; Missana et al., 2003).

* E-mail: natalia.mayordomo@ciemat.es DOI: 10.1180/claymin.2016.051.2.08
Colloidal particles are of concern because they have been identified as responsible for the migration of radionuclides over long distances $(\sim 3 \mathrm{~km})$ in some sites (Penrose et al., 1990; Kersting et al., 1999; Novikov et al., 2006). In addition, colloid size and stability affect contaminant transport (Baik et al., 2007; Vilks \& Miller, 2009; Albarran et al., 2013; Huber et al., 2014) and retention (Alonso et al., 2007).

Clays are ubiquitous in soils and, as a consequence of their erosion, they are also found in groundwater as colloids. Bentonite is a clay consisting mainly of smectites (2:1 clay minerals), and is a candidate for backfill material in nuclear-waste repositories to prevent radionuclide migration (Dohrmann et al., 2013). Bentonite colloids released from the bentonite 
barrier surface can act as contaminant carriers when radionuclide-bentonite colloid complexes are formed and are stable in suspension (McCarthy \& Zachara, 1989).

Stability studies analyse colloid aggregation as a function of $\mathrm{pH}$, ionic strength, temperature, and the presence of different multivalent ions or organic ligands. The main measurable effect of aggregation is the increase in mean particle size.

The stability of bentonite colloids, under different chemical conditions, has been studied extensively (Lagaly \& Ziesmer, 2003; Missana et al., 2003 among many others). Bentonite colloids are unstable and are aggregated at acidic $\mathrm{pH}$ and when the ionic strength is high (Missana \& Adell, 2000; Missana et al., 2003; Tombácz \& Szekeres, 2004). However, the stability behaviour of bentonite colloids under variable groundwater conditions has scarcely been analysed. In particular, it is not completely clear whether, once aggregated, colloids can return to the fully disaggregated state if chemical conditions become favourable for their stability, or, in other words, if the aggregation process is reversible.

Within the timeframes of nuclear-waste repositories which include long-lived radionuclides with life-times of millions of years, changes in environmental conditions are expected. Recharge water (i.e. rivers, lakes, rain, water from melting ice sheets, or groundwater) may reduce groundwater salinity. Therefore, although in high-salinity scenarios where a low concentration of stable colloids is predicted (Missana et al., 2003), a decrease in ionic strength might prompt particle disaggregation which could enhance the mobility of the colloids (McDowellBoyer, 1992; Ryan \& Elimelech, 1996) and radionuclides.

The disaggregation kinetics of bentonite particles promoted by dilution in lower-ionic strength waters is analysed in the present study by measuring their size in comparison to the size of the initial stable suspension upon the change in chemical conditions.

\section{MATERIALS AND METHODS}

The bentonite used for the present experiment was the FEBEX bentonite obtained from the Cortijo de Archidona deposit (Almería, Spain). It is composed mainly of smectite (93 $\pm 2 \mathrm{wt} . \%)$, minor quartz (2 \pm 1 wt. $\%)$, plagioclase $(3 \pm 1 \mathrm{wt} . \%)$ and cristobalite $(2 \pm 1$ wt.\%, and accessory K-feldspar, calcite and tridymite. The bentonite has a cation exchange capacity (CEC) of $102 \pm 4 \mathrm{meq} / 100 \mathrm{~g}$, and a $\mathrm{N}_{2}$-BET specific area of
$33 \mathrm{~m}^{2} \mathrm{~g}^{-1}$. A comprehensive characterization of the clay can be found in Huertas et al. (2000). Purification, homo-ionization procedures and preparation of bentonite colloidal suspensions have been described elsewhere (Missana et al., 2009).

A stable suspension of a homo-ionic Na-bentonite colloid was set at $0.5 \mathrm{mM}$ using $\mathrm{NaClO}_{4}$ as the background electrolyte.

An aggregated bentonite colloid suspension was prepared by taking an aliquot of the stable suspension and bringing it to a high ionic strength using $0.1 \mathrm{M}$ $\mathrm{NaClO}_{4}$.

Disaggregation was promoted by diluting the aggregated sample in two different background electrolytes (mixed $\mathrm{NaClO}_{4}$ and $\mathrm{Na}^{+}-\mathrm{Ca}^{2+}$ ) at lower ionic strengths ( $10 \mathrm{mM}, 1 \mathrm{mM}$, and $0.5 \mathrm{mM})$.

$\mathrm{Na}^{+}-\mathrm{Ca}^{2+}$ mixed electrolyte solution was prepared by dissolving $2 \mathrm{mmol}$ of $\mathrm{CaCl}_{2} \cdot 2 \mathrm{H}_{2} \mathrm{O}$ and $4 \mathrm{mmol}$ of $\mathrm{NaCl}$ in $1 \mathrm{~L}$ of deionized water to reach an ionic strength of $10 \mathrm{mM}$. Solutions at lower ionic strengths have been prepared by dilution. The $\mathrm{Cl}^{-}$or $\mathrm{ClO}_{4}^{-}$ present in solution are inert anions with little effect on bentonite colloid stability.

\section{Aggregation and disaggregation kinetics}

Aggregation/disaggregation processes are followed by measuring the mean hydrodynamic diameter of the particles, their size distribution and their concentration in solution. Two light-scattering techniques have been used to measure the hydrodynamic diameter of bentonite particles. Photon correlation spectroscopy (PCS) was used to determine the mean hydrodynamic diameter of particles in suspension (Novich, 1984) and the highly sensitive single-particle counting (SPC) was used to analyse the size distribution of particles and their concentration (Degueldre et al., 1996b; Rossé \& Loizeau, 2003).

The original sample had a concentration of $500 \mathrm{mg} \mathrm{L}^{-1}$ but, to facilitate the comparison, the concentration of all samples was set at $2 \mathrm{mg} \mathrm{L}^{-1}$, which was imposed by the maximum dilution from $0.1 \mathrm{M}$ to $0.5 \mathrm{mM}$. This concentration is similar to colloid concentrations present in natural groundwaters (Degueldre et al., 1989, 1996a), and it is also within the range of bentonite colloid concentration recorded in bentonite erosion experiments (Missana et al., 2009). In all suspensions, the $\mathrm{pH}$ was maintained at $6.5 \pm 0.5$.

Photon correlation spectroscopy. PCS was applied to measure the mean particle hydrodynamic diameter. Experiments were carried out using a Zetasizer Nano S 
Malvern instrument in which dispersed light is detected at $173^{\circ}$ with respect to the laser source $(\lambda=633 \mathrm{~nm})$. Each solution was examined at $22^{\circ} \mathrm{C}$ in $10 \times 10 \times 45 \mathrm{~mm}$ disposable polystyrene rectangular cuvettes, by fixing the measurement position at a height of $4.65 \mathrm{~mm}$. The hydrodynamic diameter was determined as the average of three measurements resulting from three individual runs of $10 \mathrm{~s}$ duration.

Kinetic aggregation tests. Kinetic aggregation tests were carried out at a bentonite colloid concentration in suspensions of $2 \mathrm{mg} \mathrm{L}^{-1}$ and the average hydrodynamic diameter was measured by PCS for $60 \mathrm{~min}$. Attachment efficiency, $\alpha$, of colloid suspensions was calculated from equation 1 :

$$
\alpha=\frac{1}{W}=\frac{\left(\frac{\delta d_{\mathrm{h}}}{\delta t}\right)_{t \rightarrow 0}}{\left(\frac{\delta d_{\mathrm{h}}}{\delta t}\right)_{\text {fast }}}
$$

where, $d_{\mathrm{h}}$ is the hydrodynamic diameter and $W$ is the stability ratio. Attachment efficiency is the ratio between the variability of hydrodynamic diameter in a sample $\left(\frac{\delta d_{\mathrm{h}}}{\delta t}\right)_{t \rightarrow 0}$ with respect to the fast aggregation regime $\left(\frac{\delta d_{\mathrm{h}}}{\delta t}\right)_{\text {fast }}$, which is considered here as the rate of aggregation of bentonite colloids in $0.1 \mathrm{M} \mathrm{Na}^{+}-\mathrm{Ca}^{2+}$ electrolyte.

Disaggregation kinetic tests. Disaggregation kinetic tests were carried out at a bentonite colloid concentration of $2 \mathrm{mg} \mathrm{L}^{-1}$. Again, to follow the disaggregation kinetics, the average hydrodynamic diameter was measured by PCS for $60 \mathrm{~min}$. The detachment efficiency of the suspensions was evaluated using equation 2:

$$
\text { Detachment efficiency }=-\frac{\left(\frac{\delta d_{\mathrm{h}}}{\delta t}\right)_{t \rightarrow 0}}{\left(\frac{\delta d_{\mathrm{h}}}{\delta t}\right)_{\text {fast }}}
$$

Detachment efficiency is determined as the ratio of the variability of hydrodynamic diameter in a sample $\left(\frac{\delta d_{\mathrm{h}}}{\delta t}\right)_{t \rightarrow 0}$ with respect to the fast disaggregation regime $\left(\frac{\delta d_{\mathrm{h}}}{\delta t}\right)_{\text {fast }}$, which is considered to be the theoretical disaggregation rate at which to reach an initial stable hydrodynamic diameter.

\section{Size distribution}

For more detailed analyses of the stable colloid distribution after disaggregation, a single particle counter (SPC) was used. In SPC measurements, the samples were measured just after dilution, without shaking, allowing the largest particles to sediment (Degueldre et al., 1996a, 2000; Bessho \& Degueldre, 2009; García-García et al., 2009).

Single particle counter $(S P C)$. Single particle counter equipment includes two detectors: HSLIS-M50 and HVLIS-C200, developed by PMT (PartikelMesstechnik AG). HSLIS-M50 was used to measure colloidal particles in the 50-200 nm size range, whereas HVLIS-C200 was used to measure colloidal particles in the 200-5000 $\mathrm{nm}$ size range. The wavelength of the laser source was $780 \mathrm{~nm}$. Pure water from the Milli-Q Plus system was supplied to the experimental system at different flow rates: 100 and $500 \mathrm{~mL} \mathrm{~min}^{-1}$ for measurements in HSLIS-M50 and HVLIS-C200, respectively. Polystyrene latex spheres of different nominal size were used as standards to calibrate the SPC instrument. Correlation factors associated with each channel were calculated for sample measurements.

The raw data measured were computerized using Facility Net, the specialized software for particlemeasuring systems. This software produces the colloid concentration corresponding to each size range in the test solution, which is prepared by diluting small amounts of original samples $\left(5 \mathrm{mg} \mathrm{L}^{-1}\right)$ with their corresponding electrolytes and injecting to the instrument by pump suction and mobilized by the water inlet. The colloid concentration recorded for a particular size range is normalized as a function of the size class, taken as the mean diameter of the corresponding channel. Thus, the normalized concentration $(\delta N / \delta d)$ is expressed in $\mathrm{mL}^{-1} \mathrm{~nm}^{-1}$ (equation 3):

$$
\frac{\delta N}{\delta d}=\frac{\left[N_{\left(d_{\min }, d_{\max }\right)}\right]}{d_{\max }-d_{\min }}
$$

Pareto's law was applied to fit the experimental data. Pareto's law establishes that the normalized concentration the $(\delta N / \delta d)$ in $\mathrm{mL}^{-1} \mathrm{~nm}^{-1}$, is related to the mean diameter $(d)$, according to equation 4 :

$$
\frac{\mathrm{d} N}{\mathrm{~d} d}=A d^{-b}
$$

where $A$ and $b$ are fitting parameters. The parameter $b$ can be obtained as the slope of the logarithmic form of equation 4.

Pareto's law has been applied to describe populations of natural colloids found in nature. This law can 
also be applied to settling particle velocity (BrunCottan, 1976; Hawley, 1982).

The parameter $b$ is related to the main processes affecting colloid stability so that it delimits the areas where aggregation is favoured or not (Lerman, 1979). For $b \leq 4$, the difference between the population of small and large particles is small and aggregation is favoured and for $b \geq 4$, the difference between the population of small and large particles is pronounced, indicating that aggregation should not be favoured (Degueldre et al., 1996a,b).

\section{RESULTS AND DISCUSSION}

\section{Aggregation kinetics}

The evolution of the mean hydrodynamic diameter, just after aggregation by increasing the ionic strength from $0.5 \mathrm{mM}$ in $\mathrm{NaClO}_{4}$ (stable suspension) to different ionic strengths in $\mathrm{Na}^{+}$or $\mathrm{Na}^{+}-\mathrm{Ca}^{2+}$ mixed electrolytes is illustrated (Figs 1a,b, respectively). The diameter of the bentonite particles in the stable suspension was $340 \pm 10 \mathrm{~nm}$.

Fast aggregation to hydrodynamic diameter of $>1 \mu \mathrm{m}$, occurred for ionic strengths of $>10 \mathrm{mM}$ in the case of a $\mathrm{Na}^{+}-\mathrm{Ca}^{2+}$ electrolyte and at $0.1 \mathrm{M}$ in the case of $\mathrm{NaClO}_{4}$. In the $\mathrm{Na}^{+}-\mathrm{Ca}^{2+}$ electrolyte, aggregation is faster due to the aggregating effect of $\mathrm{Ca}^{2+}$ according to the Schulze-Hardly rule (Hiemenz \& Rajagopalan, 1997). At the lowest ionic strength (0.5 $\mathrm{mM}$ ) the colloid diameter remained fairly constant at $340 \pm 10 \mathrm{~nm}$ in $\mathrm{Na}^{+}$electrolyte and increased slightly to $360 \pm 12 \mathrm{~nm}$ in $\mathrm{Na}^{+}-\mathrm{Ca}^{2+}$ electrolyte. By increasing the ionic strength to $1 \mathrm{mM}$, the bentonite colloid hydrodynamic mean diameter was $340 \pm 45 \mathrm{~nm}$ in $\mathrm{Na}^{+}$ electrolyte and $340 \pm 26 \mathrm{~nm}$ in $\mathrm{Na}^{+}-\mathrm{Ca}^{2+}$ electrolyte. In the time frame of the present experiments, no relevant changes in hydrodynamic diameter were observed when the ionic strength increased to $10 \mathrm{mM}$ in $\mathrm{NaClO}_{4}$ $(390 \pm 74 \mathrm{~nm})$. In the $\mathrm{Na}^{+}-\mathrm{Ca}^{2+}$ electrolyte, however, the particle hydrodynamic diameter increased significantly to $1220 \pm 490 \mathrm{~nm}$ at $10 \mathrm{mM}$. At ionic strengths of $>1 \times 10^{-2} \mathrm{M}$, the bentonite colloid hydrodynamic diameter is greater in case of the $\mathrm{Na}^{+}-\mathrm{Ca}^{2+}$ electrolyte because of the attaching properties of $\mathrm{Ca}^{2+}$. At $0.1 \mathrm{M}$, aggregation is promoted in both electrolytes, reaching average hydrodynamic diameters of $1200 \pm 260 \mathrm{~nm}$ in $\mathrm{Na}^{+}$electrolyte and $1320 \pm 470 \mathrm{~nm}$ in the $\mathrm{Na}^{+}-\mathrm{Ca}^{2+}$ electrolyte.

Particles begin to aggregate when the repulsive forces weaken or become attractive. In the present study aggregation was promoted by increasing the ionic strength of the suspensions. Other factors in deep geological repositories, such as particle concentration, temperature or pressure, can also favour aggregation because greater numbers of particles in suspension enhance colloid interaction and larger sizes are encountered.

The maximum aggregation of a system is difficult to define, but it can be related to the aggregation rate measured in the fast regime, which is achieved when the diffuse double layer is supressed and the interaction potential between the particles is purely attractive. Thus, the aggregation derived from PCS experiments can be described by the attachment efficiency coefficients (equation 1). The attachment coefficients,

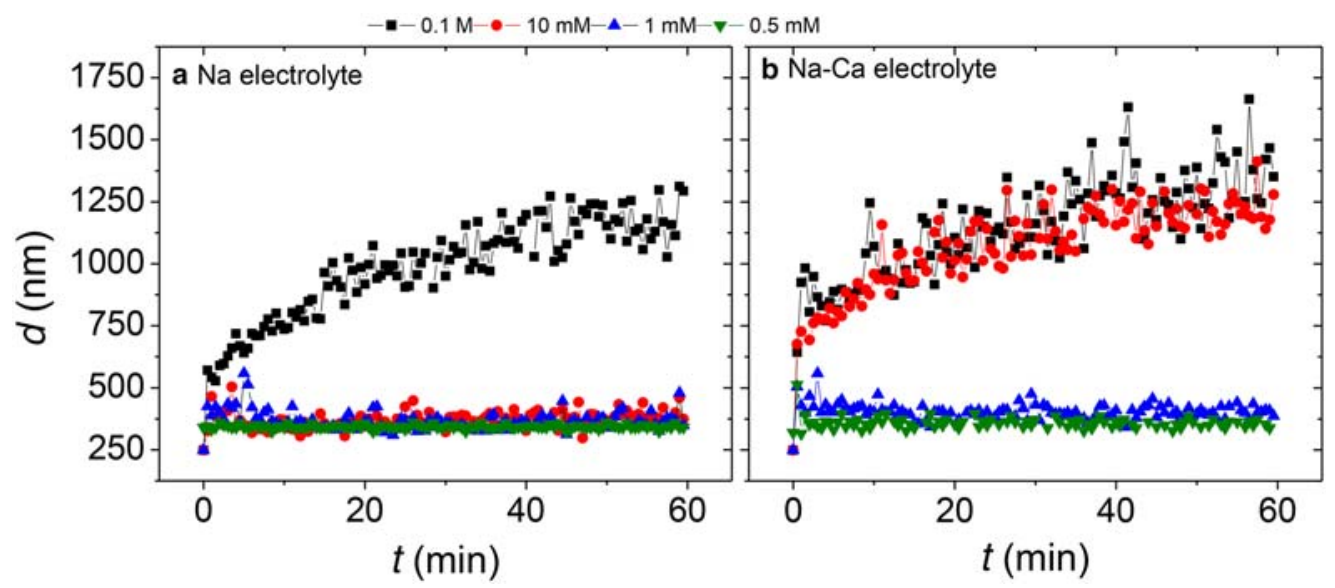

FIG. 1. Mean hydrodynamic diameter of bentonite suspensions measured as a function of time on different ionic strengths $(I)$ and electrolyte background: (a) $\mathrm{NaClO}_{4}$ and (b) $\mathrm{NaCl}-\mathrm{CaCl}_{2}$ corresponding to the aggregation kinetics. 


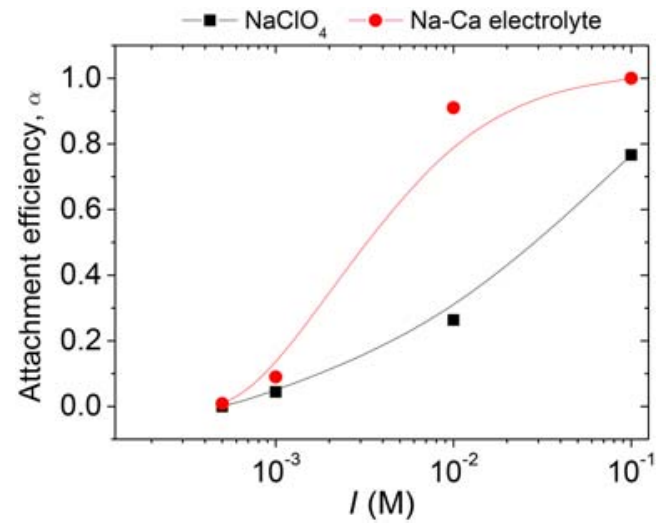

FIG. 2. Attachment efficiency, $\alpha$, of suspensions at different ionic strengths $(I)$ and electrolyte backgrounds $-\mathrm{Na}-\mathrm{Ca}$ mixed electrolyte (•) and $\mathrm{NaClO}_{4}(\boldsymbol{\bullet})$. The fast regime was taken as bentonite aggregation in $\mathrm{NaCl}-\mathrm{CaCl}_{2}$ electrolyte at $0.1 \mathrm{M}$.

$\alpha$, are the parameters generally used in stability models. Their values range from 0 to 1 , with 1 corresponding to the aggregation state in the fast regime, and 0 to a stable suspension.

To calculate $\alpha$, the initial slope on individual aggregation kinetics shown in Fig. 1 was compared to the fastest aggregation regime, considered here as that of bentonite colloid suspension at $0.1 \mathrm{M}$ in the mixed $\mathrm{Na}^{+}-\mathrm{Ca}^{2+}$ electrolyte. The attachment efficiencies corresponding to ionic strength and electrolyte background are presented in Fig. 2.
The attachment efficiency increases with increasing ionic strength in both electrolytes because interactions between particles are favoured. Differences in attachment efficiencies between electrolytes are perceived at the highest ionic strength value, when $\mathrm{Ca}^{2+}$ concentration in solution increases, resulting in enhanced particle coagulation due to attachment capability of $\mathrm{Ca}^{2+}$, as has been observed previously (Degueldre et al., 1996b, 2000; Missana et al., 2003).

In suspensions with greater ionic strength, as aggregation advanced, the hydrodynamic diameter of the particles continued to increase over time, because suppression of the diffuse double layer favoured colloid interactions and attachment, thus destabilizing the suspension.

\section{Disaggregation kinetics}

Disaggregation experiments were carried out starting with an aggregated bentonite colloid suspension in $\mathrm{NaClO}_{4}$ at $0.1 \mathrm{M}$ with an initial mean hydrodynamic particle diameter of $3400 \pm 450 \mathrm{~nm}$ and diluting it to lower ionic strengths in $\mathrm{Na}$ or $\mathrm{Na}-\mathrm{Ca}$ electrolytes.

To evaluate the kinetics of disaggregation, timeresolved measurements were carried out by PCS for $60 \mathrm{~min}$ (Fig. 3). The hydrodynamic diameter of both the aggregated and the stable suspensions are indicated as lines.

Disaggregation occurred in all cases within $<5 \mathrm{~min}$. After $60 \mathrm{~min}$, the hydrodynamic diameters resulting from disaggregation were: at $10 \mathrm{mM}=1120 \pm 390 \mathrm{~nm}$
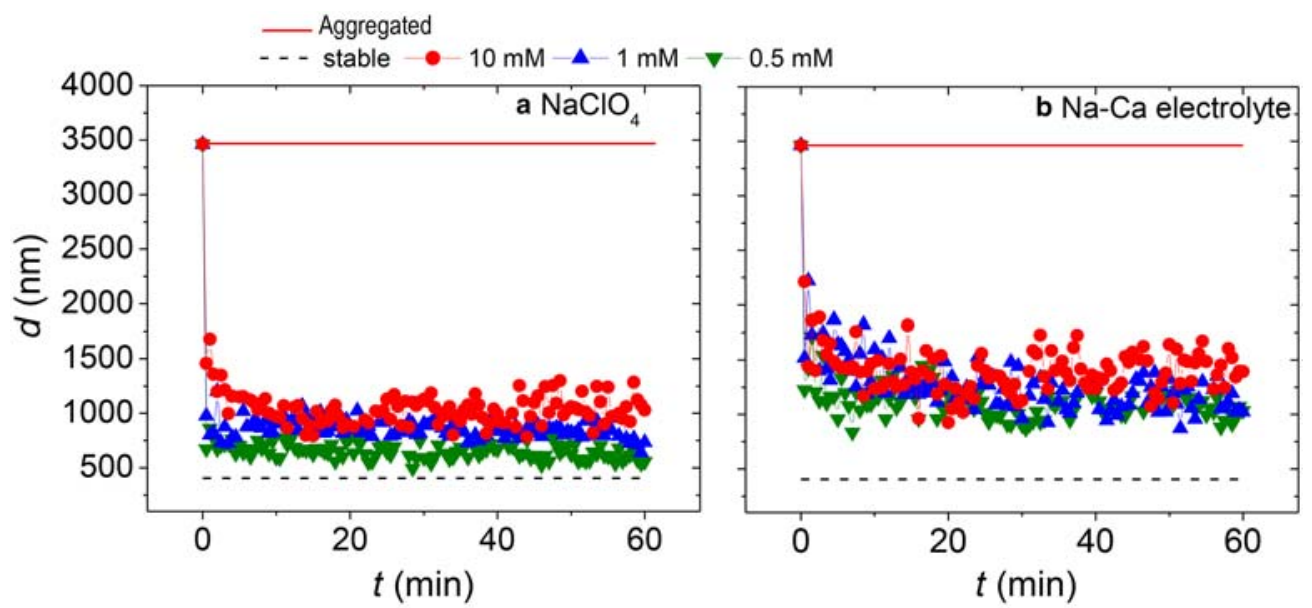

FIG. 3. Mean hydrodynamic diameter of bentonite suspensions measured as a function of time on different ionic strengths $(I)$ and electrolyte background: (a) $\mathrm{NaClO}_{4}$ and (b) $\mathrm{NaCl}-\mathrm{CaCl}_{2}$, corresponding to the disaggregation kinetics. 
in $\mathrm{Na}^{+}$electrolyte and $1450 \pm 220 \mathrm{~nm}$ in $\mathrm{Na}^{+}-\mathrm{Ca}^{2+}$ electrolyte; at $1 \mathrm{mM}=870 \pm 150 \mathrm{~nm}$ in $\mathrm{Na}^{+}$electrolyte and $1350 \pm 245 \mathrm{~nm}$ in $\mathrm{Na}^{+}-\mathrm{Ca}^{2+}$ electrolyte; and at $0.5 \mathrm{mM}=685 \pm 300 \mathrm{~nm}$ in $\mathrm{Na}^{+}$electrolyte and $870 \pm$ $400 \mathrm{~nm}$ in $\mathrm{Na}^{+}-\mathrm{Ca}^{2+}$ electrolyte. It follows that the final size decreases with decreasing ionic strength, but the initial stable hydrodynamic diameter $(340 \pm 10 \mathrm{~nm})$ is not recovered, suggesting that once the bentonite colloids are aggregated, disaggregation is not complete, even in $\mathrm{Ca}^{2+}$-free solutions. Even when the aggregated bentonite colloids at $0.1 \mathrm{M} \mathrm{NaClO}_{4}$ are diluted in deionized water, the hydrodynamic diameter of the recovered bentonite colloid was $486 \pm 72 \mathrm{~nm}$, indicating that the process is irreversible at least in the time frame of the present experiment.

Similarly, the time-resolved data were used to derive detachment coefficients (equation 2). The detachment efficiency was determined in this case as the ratio of diameter decrease $\left(\frac{\delta d_{\mathrm{h}}}{\delta \mathrm{t}}\right)_{t \rightarrow 0}$ corresponding to the fast disaggregation regime. The initial size of the stable suspension was not recovered and the fast disaggregation regime, $\left(\frac{\delta d_{\mathrm{h}}}{\delta \mathrm{t}}\right)_{\text {fast }}$, could not be determined experimentally. The value considered was provided by the sigmoidal curve used to fit the measured $\left(\frac{\delta \mathrm{d}_{\mathrm{h}}}{\delta \mathrm{t}}\right)_{t \rightarrow 0}$ corresponding diameter in $\mathrm{NaClO}_{4}$ electrolyte.

Figure 4 shows the detachment coefficients calculated by applying equation 2 to the disaggregation kinetics experiments (Fig. 3). The detachment efficiency ranges from 0 to -1 , where 0 corresponds to the less prompted disaggregation process and -1 corresponds to the most favourable disaggregation conditions.

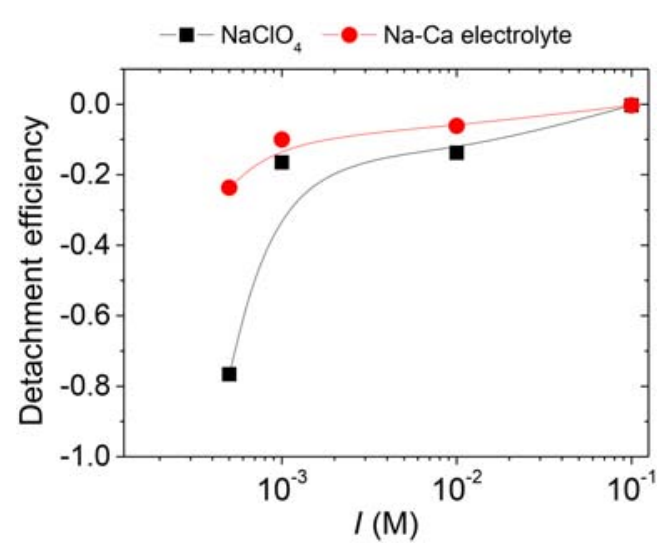

FIG. 4. Detachment efficiency of suspensions at different ionic strengths $(I)$ and electrolyte backgrounds $-\mathrm{NaCl}-$ $\mathrm{CaCl}_{2}(\bullet)$ and $\mathrm{NaClO}_{4}(\mathbf{\bullet})$. The fast regime was taken as the slope to reach initial stable size.
The detachment efficiencies determined for bentonite colloids increased with decreasing ionic strength in both electrolytes because repulsive forces enhance, and the steric hindrance avoids, particle attachment. Disaggregation is more efficient in the case of the
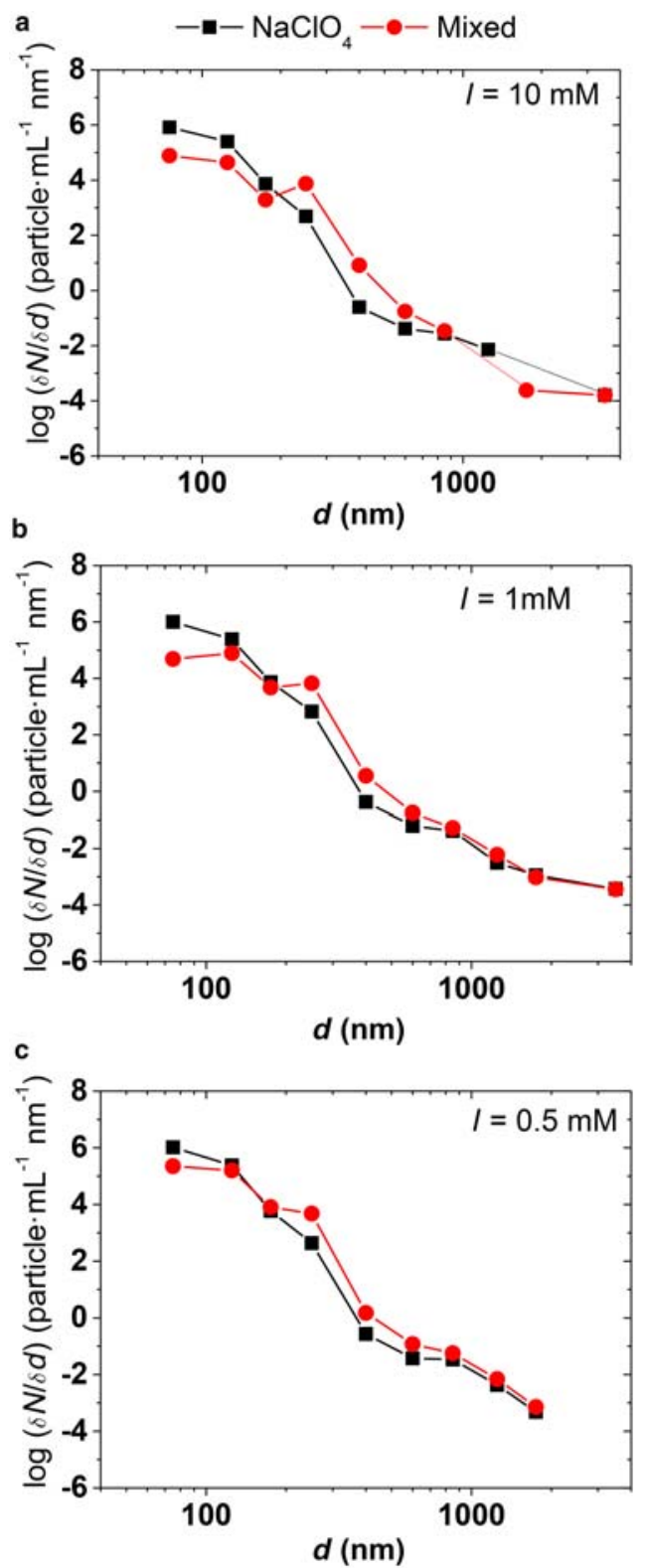

FIG. 5. Size distribution of suspensions in $\mathrm{NaCl}-\mathrm{CaCl}_{2}(\bullet)$ and $\mathrm{NaClO}_{4}$ (घ) at different ionic strengths: (a) $10 \mathrm{mM}$; (b) $1 \mathrm{mM}$; and (c) $0.5 \mathrm{mM}$. 
$\mathrm{NaClO}_{4}$ electrolyte, whereby absolute values up to 0.8 were attained, indicating that disaggregation is favoured at the lowest ionic strength and in the absence of $\mathrm{Ca}^{2+}$, as was also observed for other bentonites (Kaufhold \& Dohrmann, 2008). When comparing detaching efficiencies at a fixed ionic strength, differences between electrolytes are better observed when the ionic strength is lower.

Complete disaggregation was not obtained because the maximum detachment efficiency $(-1)$ was not achieved (Fig. 4). Moreover, the initial stable hydrodynamic diameter was not fully recovered, at least within the time frame of our experiments.

\section{Size distribution}

Single Particle Counter (SPC) was applied to indepth analysis of the size distribution of bentonite particles after disaggregation. Samples that were taken from the middle of the batch were not shaken to avoid particle sedimentation, facilitating the analysis of the stable fractions (Degueldre et al., 2000). The normalized particle concentrations, measured in different size intervals, on bentonite colloids disaggregated by dilution to lower ionic strengths, are plotted in Fig. 5.

In both electrolytes, the particle concentration decreased with increasing size. In the presence of $\mathrm{Na}^{+}$ electrolyte the $50-100 \mathrm{~nm}$ size detector channel is the most populated, whereas in the $\mathrm{Na}^{+}-\mathrm{Ca}^{2+}$ electrolyte the most populated size channels are within 50 and $300 \mathrm{~nm}$, being greater for diameters of $>200 \mathrm{~nm}$, as $\mathrm{Ca}^{2+}$ hinders disaggregation.

This trend was also observed recently during analysis of the size distribution of bentonite colloids generated in different electrolytes (Albarran et al., 2014). With increasing amounts of $\mathrm{Ca}^{2+}$, the concentration of particles in the lower hydrodynamic diameter channels $(<150 \mathrm{~nm})$ decreased.

It is remarkable that, even at high ionic strengths, and in the presence of $\mathrm{Ca}$, small colloids were detected in disaggregated samples. Nevertheless, the total particle concentration measured by SPC in disaggregated samples is less than that in $0.5 \mathrm{mM} \mathrm{NaClO}_{4}$, which is the initial stable suspension. Table 1 lists the concentration ratios obtained by comparing the concentration values (Fig. 5) to that of the stable bentonite colloid suspension in $0.5 \mathrm{mM} \mathrm{NaClO}_{4}$. Suspensions in $\mathrm{NaClO}_{4}$ have a concentration ratio very close to that of primary suspension $(\sim 0.91$ on average), but in the presence of $\mathrm{Ca}^{2+}$, the ratio of concentration of disaggregated particles is small compared to the original one ( 0.3 at best). Other studies have also discovered lower bentonite colloid generation in groundwater with divalent cations (e.g. Missana et al., 2011).

Pareto's law was applied to the normalized concentration of particles $(\delta N / \delta d)$ measured by SPC, using equation 4 . Table 2 shows the $b$ parameters obtained by linear regression of the whole curves. Parameter $b$ is greater in bentonite colloids disaggregated in $\mathrm{NaClO}_{4}$, in agreement with the fact that $\mathrm{Ca}^{2+}$ hinders disaggregation, but the $b$ parameter always exceeds 4 nonetheless. Previous studies have reported $b$ values of 3-5 in natural waters (Rossé \& Loizeau, 2003; Gregory, 2006; Jonasz, 2007). Larger values (up to $b=$ 20 ) have also been reported in waters (Attela \& Kozel, 1997; Jonasz, 2007). Other works have reported $b$ values of $\sim 4$ for groundwater colloids (Degueldre

TABLE 1. Concentration (particles, $\mathrm{mL}^{-1} \mathrm{~nm}^{-1}$ ) ratio of stable bentonite colloid concentrations, measured by SPC in disaggregated suspensions, with respect to the initial stable bentonite suspension at $0.5 \mathrm{mM} \mathrm{NaClO}_{4}$, in the $(50-5000) \mathrm{nm}$ size range.

\begin{tabular}{lc}
\hline Experiment & $\begin{array}{c}\text { Particle concentration } \\
\text { measured/stable } \\
\text { particle concentration }\end{array}$ \\
\hline From $0.1 \mathrm{M}$ to $10 \mathrm{mM} \mathrm{NaClO}_{4}$ & 0.82 \\
From $0.1 \mathrm{M}$ to $1 \mathrm{mM} \mathrm{NaClO}$ & \\
From $0.1 \mathrm{M}$ to $0.5 \mathrm{mM} \mathrm{NaClO}_{4}$ & 0.95 \\
From $0.1 \mathrm{M}$ to $10 \mathrm{mM} \mathrm{NaCl}-\mathrm{CaCl}_{2}$ & 0.97 \\
From $0.1 \mathrm{M}$ to $1 \mathrm{mM} \mathrm{NaCl}-\mathrm{CaCl}_{2}$ & 0.10 \\
From $0.1 \mathrm{M}$ to $0.5 \mathrm{mM} \mathrm{NaCl}-\mathrm{CaCl}_{2}$ & 0.11 \\
& 0.30
\end{tabular}


TABLE 2. Pareto law's $b$ parameter, obtained on the size range (50-5000) $\mathrm{nm}$ of disaggregated colloidal bentonite suspensions at different ionic strengths and using different electrolytes.

\begin{tabular}{|c|c|}
\hline Sample & Whole curve \\
\hline $\mathrm{NaClO}_{4} 10 \mathrm{mM}$ & $6.6 \pm 1.2$ \\
\hline $\mathrm{NaClO}_{4} 1 \mathrm{mM}$ & $6.0 \pm 0.5$ \\
\hline $\mathrm{NaClO}_{4} 0.5 \mathrm{mM}$ & $6.7 \pm 1.2$ \\
\hline $\mathrm{NaCl}-\mathrm{CaCl}_{2} 10 \mathrm{mM}$ & $6.1 \pm 0.6$ \\
\hline $\mathrm{NaCl}-\mathrm{CaCl}_{2} 1 \mathrm{mM}$ & $6.4 \pm 0.6$ \\
\hline $\mathrm{NaCl}-\mathrm{CaCl}_{2} 0.5 \mathrm{mM}$ & $6.5 \pm 0.6$ \\
\hline
\end{tabular}

et al., 2000; van Beek et al., 2010 and references therein). Values of $>4$ are related to stable colloids which are potentially mobile, whereas smaller $b$ values are attributed to less stable suspensions with restricted mobility (Degueldre et al., 2000).

In safety analyses of nuclear-waste repositories in crystalline rocks, bentonite colloid disaggregation may occur over the long term. In those repositories emplaced in geological formations with highly saline groundwater usually rich in divalent cations, such as in the Scandinavian Peninsula (Backblom, 1991), experimental and model exercises predict negligible colloid concentration (Missana et al., 2003; Chen \& Huang, 2013; Gimeno et al., 2014; Gómez et al., 2014). However, within the time frames of nuclear waste repositories, changes in environmental conditions are expected and fresh water inflow may reduce groundwater salinity (e.g. the melting waters from ice sheets) favouring bentonite particle disaggregation.

\section{SUMMARY}

Previous dynamic colloid-transport studies showed that the relevance of particle diameter (Baik et al., 2007; Vilks \& Miller, 2009; Albarran et al., 2013; Huber et al., 2014), therefore, and the potential risk of bentonite colloids, disaggregated upon quick dilution, being contributors to radionuclide migration within repository host rock, would be limited if particles were large or unstable. Disaggregation of bentonite colloids is promoted effectively by decreasing ionic strength, but the process is not fully reversible and initial stable hydrodynamic diameters are not recovered, even at lower ionic strengths and in the absence of divalent cations. Nonetheless, the possibility of further disaggregation over longer time periods is not discounted.

\section{CONCLUSIONS}

Disaggregation of FEBEX bentonite colloids promoted by dilution to lower ionic strength was studied using Photon Correlation Spectroscopy (PCS) and Single Particle Counting (SPC). The disaggregation was initially quick, but a completely disaggregated state was not achieved, even at low ionic strength and in the absence of divalent cations. In the presence of divalent cations, the stable portion of disaggregated colloids was very small compared to the original sample $(<10 \%)$ even at the lowest ionic strength, but it was $\sim 70 \%$ in the absence of $\mathrm{Ca}$. Partially disaggregated particles would have restricted mobility, but further disaggregation over longer times is not discounted.

\section{ACKNOWLEDGEMENTS}

N. Mayordomo acknowledges the FPI BES-2012-056603 grant from MINECO (Spain) and the EEBB-I-14-08074 short stay grant from MINECO (Spain). The research leading to these results received funding from the EU FP7/ 2007-2011 under the grant agreements $N^{\circ} 295487$ (BELBAR, Bentonite Erosion: effects on the Long term performance of the engineered Barrier and Radionuclide Transport) and from the NANOBAG Ministry of Economy and Competitiveness project.

\section{REFERENCES}

Albarran N., Missana T., Alonso U., García-Gutiérrez M., Medioambiente D. De \& Complutense A. (2013) Analysis of latex, gold and smectite colloid transport and retention in artificial fractures in crystalline rock. Colloids and Surfaces A: Physicochemical and Engineering Aspects, 435, 115-126. Elsevier, Amsterdam.

Alonso U., Missana T., Patelli A., Rigato V. \& Ravagnan J. (2007) Colloid diffusion in crystalline rock: An experimental methodology to measure diffusion coefficients and evaluate colloid size dependence. Earth and Planetary Science Letters, 259, 372-383.

Attela O. \& Kozel R. (1997) Particle size distributions in waters from a karstic aquifer: From particles to colloids. Journal of Hydrology, 201, 102-119.

Backblom G. (1991) The Äspö Hard Rock Laboratory—a step toward the Swedish final repository for high-level radioactive waste. Tunnelling and Underground Space Technology, 6, 463-467.

Baik M.H., Cho W.J. \& Hahn P.S. (2007) Erosion of bentonite particles at the interface of a compacted bentonite and a fractured granite. Engineering Geology, 91, 229-239. 
Bessho K. \& Degueldre C. (2009) Generation and sedimentation of colloidal bentonite particles in water. Applied Clay Science, 43, 253-259.

Brun-Cottan J.-C. (1976) Stokes settling and dissolution rate model for marine particles as function of size distribution. Journal of Geophysical Research, 81, 1601-1606.

Chen W.-C. \& Huang W.-H. (2013) Effect of groundwater chemistry on the swelling behavior of a Ca-bentonite for deep geological repository. Physics and Chemistry of the Earth, 65, 42-49.

Degueldre C., Baeyens B., Goerlich W., Riga J., Verbist J. \& Stadelmann P. (1989) Colloids in water from a subsurface fracture in granitic rock, Grimsel Test Site, Switzerland. Geochimica et Cosmochimica Acta, 53, 603-610.

Degueldre C., Pfeiffer H.R., Alexander W., Wernli B. \& Bruetsch R. (1996a) Colloid properties in granitic groundwater systems. I: Sampling and characterisation. Applied Geochemistry, 11, 677-695.

Degueldre C., Grauer R., Laube A., Oess A. \& Silby H. (1996b) Colloid properties in granitic groundwater systems. II: Stability and transport study. Applied Geochemistry, 11, 697-710.

Degueldre C., Triay I., Kim J.-I., Vilks P., Laaksoharju M. \& Miekeley N. (2000) Groundwater colloid properties: a global approach. Applied Geochemistry, 15, 1043-1051.

Degueldre C., Aeberhard P., Kunze P. \& Bessho K. (2009) Colloid generation/elimination dynamic processes: Toward a pseudo-equilibrium? Colloids and Surfaces A: Physicochemical and Engineering Aspects, 337, 117-126.

Dohrmann R., Kaufhold S. \& Lundqvist B. (2013) The role of clays for safe storage of nuclear waste. Pp. 667-710 in: Handbook of Clay Science (F. Bergaya \& G. Lagaly, editors). Elsevier, Amsterdam.

García-García S., Degueldre C., Wold S. \& Frick S. (2009) Determining pseudo-equilibrium of montmorillonite colloids in generation and sedimentation experiments as a function of ionic strength, cationic form, and elevation. Journal of Colloid and Interface Science, 335, 54-61.

Gimeno M.J., Auqué L.F., Acero P. \& Gómez J.B. (2014) Hydrogeochemical characterisation and modelling of groundwaters in a potential geological repository for spent nuclear fuel in crystalline rocks (Laxemar, Sweden). Applied Geochemistry, 45, 50-71.

Gómez J.B., Gimeno M.J., Auqué L.F. \& Acero P. (2014) Characterisation and modelling of mixing processes in groundwaters of a potential geological repository for nuclear wastes in crystalline rocks of Sweden. Science of the Total Environment, 468-469, 791-803.

Gregory J. (2006) Particles in water: Properties and Processes. Taylor \& Francis, Boca Raton, Florida, USA.
Hawley N. (1982) Settling velocity distribution of natural aggregates. Journal of Geophysical Research, 87, 9489.

Hiemenz P.C. \& Rajagopalan R. (1997) Principles of Colloid \& Surface Chemistry. Third edition. Marcel Dekker Inc., New York.

Huber F., Noseck U. \& Schäfer T. (2014) Colloid/ nanoparticle formation and mobility in the context of deep geological nuclear waste disposal. Project KOLLORADO-2 Final Report.

Huertas F., Fuentes-Santillana J.L., Jullien F., Rivas P., Linares J., Fariña P., Ghoreychi M., Jockwer N., Kickmaier W., Martínez M., Samper J., Alonso E. \& Elorza F.J. (2000) FEBEX project final report, EUR 19147. Madrid.

Jonasz M. (2007) Light Scattering by Particles in Water: Theoretical and Experimental Foundations. Elsevier, Amsterdam.

Kaufhold S. \& Dohrmann R. (2008) Detachment of colloidal particles from bentonites in water. Applied Clay Science, 39, 50-59.

Kersting A.B., Efurd D.W., Finnegan D.L., Rokop D.J., Smith D.K. \& Thompson J.L. (1999) Migration of plutonium in ground water at the Nevada Test Site. Nature, 397, 56-59.

Lagaly G. \& Ziesmer S. (2003) Colloid chemistry of clay minerals: The coagulation of montmorillonite dispersions. Advances in Colloid and Interface Science, 100102, 105-128.

Lerman A. (1979) Geochemical Processes. Water and Sediment Environment. Cambridge University Press, New York.

McCarthy J.F. \& Zachara J.M. (1989) Subsurface transport of contaminants: binding to mobile and immobile phases in groundwater aquifers. Environmental Science \& Technology, 23, 496-502.

McDowell-Boyer L.M. (1992) Chemical mobilization of micron-sized particles in saturated porous media under steady flow conditions. Environmental Science \& Technology, 26, 586-593.

Missana T. \& Adell A. (2000) On the applicability of DLVO theory to the prediction of clay colloids stability. Journal of Colloid and Interface Science, 230, 150-156.

Missana T., Alonso U. \& Turrero M.J. (2003) Generation and stability of bentonite colloids at the bentonite/ granite interface of a deep geological radioactive waste repository. Journal of Contaminant Hydrology, 61, 17-31.

Missana T., Alonso U. \& García-Gutiérrez M. (2009) Experimental study and modelling of selenite sorption onto illite and smectite clays. Journal of Colloid and Interface Science, 334, 132-8.

Missana T., Alonso U., Albarran N., García-Gutiérrez M. \& Cormenzana J.L. (2011) Analysis of colloids erosion from the bentonite barrier of a high level radioactive waste repository and implications in safety 
assessment. Physics and Chemistry of the Earth, 36, 1607-1615.

Novich B.E. (1984) Colloid stability of clays using photon correlation spectroscopy. Clays and Clay Minerals, 32, 400-406.

Novikov A.P., Kalmykov S.N., Utsunomiya S., Ewing R. C., Horreard F., Merkulov A., Clark S.B., Tkachev V. V. \& Myasoedov B.F. (2006) Colloid transport of plutonium in the far-field of the Mayak Production Association, Russia. Science (New York, N.Y.), 314, 638-641.

Penrose W.R., Polzer W.L., Essington E.H., Nelson D.M. \& Orlandini K.A. (1990) Mobility of plutonium and americium through a shallow aquifer in a semiarid region. Environmental Science and Technology, 24, 228-234.

Rossé P. \& Loizeau J.-L. (2003) Use of single particle counters for the determination of the number and size distribution of colloids in natural surface waters.
Colloids and Surfaces A: Physicochemical and Engineering Aspects, 217, 109-120.

Ryan J.N. \& Elimelech M. (1996) Colloid mobilization and transport in groundwater. Colloids and Surfaces A: Physicochemical and Engineering Aspects, 107, 1-56.

Tombácz E. \& Szekeres M. (2004) Colloidal behavior of aqueous montmorillonite suspensions: The specific role of $\mathrm{pH}$ in the presence of indifferent electrolytes. Applied Clay Science, 27, 75-94.

Van Beek C.G.E.M., de Zwart A.H., Balemans M., Kooiman J.W., van Rosmalen C., Timmer H., Vandersluys J. \& Stuyfzand P.J. (2010) Concentration and size distribution of particles in abstracted groundwater. Water Research, 44, 868-878. Vilks P. \& Miller N.H. (2009) Limited Bentonite and Latex Colloid Migration Experiments in a Granite Fracture on a Metre Scale to Evaluate Effects of Particle Size and Flow. Nuclear Waste Management Organization TR-2009-26. 